\title{
Educação e ludicidade: um diálogo com a Pedagogia Waldorf
}

\section{Education and ludicity: a dialogue with the Waldorf Pedagogy}

\author{
Dulciene Anjos de Andrade e Silva ${ }^{1}$
}

\begin{abstract}
RESUMO
Este artigo busca relacionar os princípios e fundamentos da Pedagogia Waldorf, iniciativa educacional concebida por Rudolf Steiner, orientada epistemológica e didático-metodologicamente para a formação multidimensional do educando, com o conceito de ludicidade desenvolvido por Cipriano Luckesi: um estado interno do sujeito que age e/ou vivencia uma atividade de forma plena. Identifica que, ao transcender a concepção reducionista e instrumental do processo de aprendizagem e voltar-se para a integração do pensar, sentir e fazer no processo formativo do educando, a Pedagogia Waldorf apresenta-se como um modelo efetivo de educação lúdica e, portanto, consoante com o paradigma educacional da contemporaneidade.

Palavras-chave: formação global do educando; ludicidade; Pedagogia Waldorf.
\end{abstract}

\begin{abstract}
This article aims to relate the principles and foundations of Waldorf Pedagogy, an educational school of thought founded by Rudolf Steiner, epistemologically, methodologically and didactically guided to a multidimensional formation of students, with the concept of ludicity developed by Cipriano Luckesi, defined as the internal or subjective state of one who fully experiences or acts in a form of activity. Waldorf Pedagogy transcends the traditional instrumental and reductionist conception of the learning process to focus on the integration of thinking, feeling and doing in students' educational processes; it has thus proven itself to be a fitting model of playful
\end{abstract}

DOI: $10.1590 / 0104-4060.41463$

1 Universidade do Estado da Bahia. Departamento de Educação II. Alagoinhas, Bahia, Brasil. Rodovia Alagoinhas - Salvador, BR-110, Km 03. CEP: 48.040-210.E-mail: dasilva@uneb.br 
education and furthermore a model for meeting the educational needs and challenges of contemporaneity.

Keywords: holistic education; ludicity; Waldorf Pedagogy.

\section{Para começo de conversa...}

A educação moderna, herdeira da tradição epistemológica racionalista e mecanicista, ao reproduzir a fragmentação entre as instâncias da experiência humana, caracterizou-se por instituir um ensino eminentemente voltado para a aprendizagem cognitiva conceitual, promovendo uma dissociação entre o pensar, o sentir e o fazer do educando e, deste modo, desprezando toda a experiência subjetiva, estética e lúdica no processo de aprendizagem. Entretanto, no início do século XX, as descobertas realizadas pela ciência deram início a um modo de compreender o homem e a realidade a partir da inter-relação entre elementos e qualidades desses fenômenos. Essa tendência tem igualmente se expressado no pensamento educacional emergente, de modo que vários são os estudos que têm buscado reintegrar o que fora descartado na educação moderna em função da ênfase ao racionalismo estrito.

Tais estudos têm chamado a atenção para a necessidade de se promover uma educação que, superando a abordagem conteudista e instrumental, não esteja focada apenas no desenvolvimento da racionalidade, do cognitivo dos educandos, mas que também considere o seu desenvolvimento emocional e afetivo, o cultivar de sua sensibilidade e de suas habilidades sociais, enfim, uma educação que, transcendendo a ênfase no pensar, e buscando um processo de aprendizagem significativo para os estudantes, possa também orientar-se para o sentir e o fazer do educando, voltando-se para o desenvolvimento do SER inteiro. Nesse contexto, as proposições que versam sobre a importância da experiência lúdica como um recurso básico para esse desenvolvimento integral do educando têm-se destacado, adquirindo uma posição privilegiada no pensamento educacional.

Embora esse movimento aponte para uma revisão urgente nos princípios e procedimentos da prática pedagógica, um olhar atento às salas de aula possibilita constatar que o dia a dia das escolas do sistema oficial de ensino não tem se mostrado consoante com o paradigma científico da atualidade, refletindo, ainda, a concepção abstrata e mecânica do processo de aprendizagem e espelhando o enorme hiato entre o pensar, o sentir e o fazer; entre corpo e mente; entre inteligência, sensibilidade e afetividade. E, uma vez ainda focado numa 
racionalidade instrumental, o processo de ensino-aprendizagem está muito distante de um enfoque verdadeiramente lúdico, de modo que o que comumente se observa quando se pretende "ensinar ludicamente" é, por um lado, a realização de atividades brincantes descontextualizadas em sala de aula, sem que se tenha clareza da devida correspondência entre os objetivos de tais atividades e os que se pretende assegurar, ou, por outro lado, a promoção de ações igualmente isoladas que são valorizadas não pelo valor intrínseco de sua função educativa, mas sim pela função utilitarista que assumem, já que, nesses casos, servem sempre como meio para transmitir conteúdos teóricos.

Em minha tese de doutorado (2010), ao buscar aprofundar a compreensão das relações entre educação integral e desenvolvimento da expressão oral dos educandos, me deparei com uma iniciativa educacional que, na contramão da tendência hegemônica nas instituições escolares, tem avançado quanto à concepção e ao método de educação por apresentar uma orientação lúdica e integradora para o processo de ensino-aprendizagem, apresentando-se consoante com os pressupostos e diretrizes destacados pelo paradigma educacional emergente. Trata-se da Pedagogia Waldorf, uma proposta de educação formal concebida e concretizada pelo filósofo austríaco Rudolf Steiner (1861-1925) em 1919, na Alemanha, e atualmente praticada em mais de 900 instituições escolares nos cinco continentes (dentre as quais 62 estão situadas no Brasil)².

Após me debruçar sobre o conceito de ludicidade elaborado por Cipriano Luckesi, que se assenta na visão integral dos fenômenos desenvolvida pelo filósofo americano Ken Wilber, buscarei relacionar tal conceito com os pressupostos epistemológicos e didático-metodológicos da Pedagogia Waldorf, anunciando como esses princípios mostram-se articulados com os alicerces de uma educação lúdica (e, portanto, voltada para o desenvolvimento da integralidade física, anímica e espiritual do educando), apresentando-se consoante aos pressupostos e diretrizes destacados para a educação da contemporaneidade.

\section{Ludicidade: o que é mesmo isto? Uma abordagem a partir da percepção interna do sujeito}

Ao refletir sobre um fazer educativo voltado para as qualidades fundamentais do ser humano, Cipriano Luckesi (2000, 2005a, 2005b) propõe

2 Dados extraídos do site da Federação das Escolas Waldorf do Brasil. Disponível em: $<$ http://www.federacaoescolaswaldorf.org.br/Historia.php>. Acesso em: 09 fev. 2015. 
uma abordagem que, centrada na ludicidade, considere o ser humano em sua totalidade, auxiliando-o não apenas cognitivamente, mas também emocional e espiritualmente. Há quinze anos dedicando-se ao estudo do tema, o filósofo e educador brasileiro propõe, de forma original, uma compreensão do fenômeno da ludicidade a partir da experiência interna do sujeito.

Para Luckesi (2000, 2005a, b), ludicidade é um estado interno do sujeito que vivencia uma experiência de forma plena, é sinônimo de plenitude da experiência - considerando aqui "plenitude da experiência" como a máxima expressão possível da não divisão entre pensar/ sentir/ fazer. Segundo ele, a ludicidade não está diretamente relacionada a jogos e brincadeiras - embora nestas atividades comumente se vislumbre a ludicidade: como brincar de "cacique", "baleado", "escravos de Jó", se nosso corpo, nossa mente e nossa emoção não estiverem presentes no momento em que as estamos vivenciando? A ludicidade está, sim, relacionada à atitude interna do indivíduo que experimenta uma experiência de integração entre seu sentir, seu pensar e seu fazer.

Desse modo, existem atividades que podem ser vivenciadas com ou sem ludicidade: se estamos em uma academia apenas realizando automaticamente o movimento físico que nos instrui o professor, sem que a nossa mente acompanhe o exercício, não a estamos vivenciando ludicamente. Entretanto, se realizamos conscientemente os exercícios, se nos mantivermos atentos ao funcionamento do nosso corpo, à nossa respiração, às nossas sensações, estaremos vivenciando tais exercícios ludicamente - muito embora academia não signifique necessariamente "uma brincadeira"... Em suas palavras:

[...] o que a ludicidade traz de novo é o fato de que o ser humano, quando age ludicamente, vivencia uma experiência plena. [...] Enquanto estamos participando verdadeiramente de uma atividade lúdica, não há lugar, na nossa experiência, para qualquer outra coisa além desta atividade. Não há divisão. Estamos inteiros, plenos, flexíveis, alegres, saudáveis. [...] Brincar, jogar, agir ludicamente exige uma entrega total do ser humano, corpo e mente ao mesmo tempo. (LUCKESI, 2000, p. 21).

Ao considerar a ludicidade como "um estado interno do sujeito que age e/ ou vivencia uma atividade lúdica”, Luckesi (2002) apresenta uma contribuição significativa para a compreensão desse fenômeno, acrescentando às abordagens correntes, em geral dedicadas às manifestações exteriores do sujeito que vivencia um jogo ou uma brincadeira, um olhar agora focado na dimensão interna do ser humano. 
Visando melhor explicitar a compreensão que tem defendido, Luckesi (2002) utiliza-se da teoria desenvolvida por Ken Wilber (1998), filósofo americano contemporâneo que, ao se debruçar sobre os estudos da consciência, propõe a integração das esferas subjetiva/espiritual e objetiva/empírica da experiência humana. Assim, esclarece que, como todo e qualquer fenômeno da experiência humana, as atividades lúdicas podem ser abordadas a partir de quatro dimensões que representam, nos dizeres de Wilber (1998, p. 55), "o interior e o exterior do indivíduo e da coletividade". Vejamos, detalhadamente, como isso funciona, partindo da exposição de Wilber para, em seguida, integrar o pensamento de Luckesi.

Para Wilber (1998), assim como o ser humano, que em sua concepção integral se expressa em quatro dimensões, também são quatro as dimensões dos fenômenos a ele relacionados - ou por ele realizados. Sintetizadas pelo autor em quatro quadrantes, essas dimensões, ao se apresentarem profundamente relacionadas e conectadas entre si, podem ser visualizadas da seguinte forma:

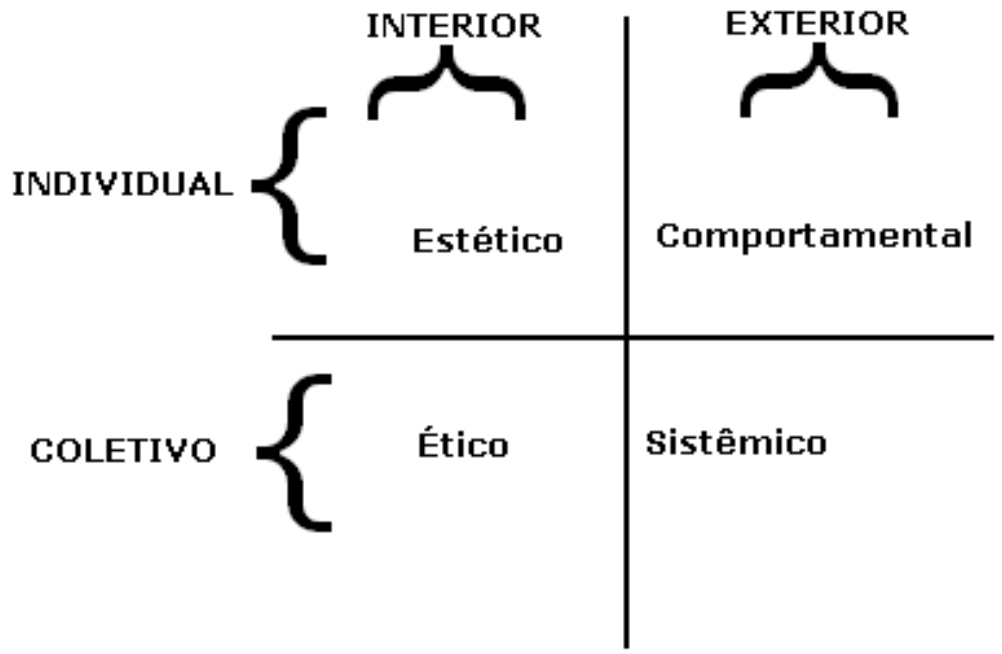

FONTE: Adaptado de Luckesi (2005a).

A dimensão interior, que diz respeito às experiências diretamente vivenciadas pelos indivíduos ou pela coletividade, subdivide-se, de acordo com 
Wilber (1998), em interior individual e interior coletiva, respectivamente correspondentes aos quadrantes esquerdos superior e inferior. O quadrante esquerdo superior, espaço da intencionalidade do sujeito, é a expressão da percepção dos indivíduos, da sua consciência individual, subjetiva, de seus sentimentos, desejos, aspirações, espiritualidade: de tudo aquilo que, exatamente por situar-se na dimensão do interior, foi negado e rejeitado pela materialidade científica e pelo positivismo. Já o quadrante esquerdo inferior, dimensão das partilhas individuais e subjetivas, de uma visão de mundo coletiva ou de um ponto de vista comum, é o espaço da coletividade, da consciência intersubjetiva, dos valores culturais, da ética e da moral, sem os quais a consciência individual não se desenvolveria nem funcionaria.

Enquanto a dimensão interior diz respeito às experiências vividas diretamente pelos indivíduos, a dimensão exterior corresponde, exatamente, à expressão objetiva destas experiências. Nos dizeres de Whitehead (apud WILBER, 1998, p. 52-64), são fenômenos que possuem "localização simples", ou seja, podem ser identificados no mundo sensório motor e empírico: é tudo aquilo que podemos ver com os nossos órgãos dos sentidos e/ou suas extensões, "tudo aquilo que podemos tocar com o dedo, literal ou figurativamente"... Por ser a versão objetiva dos componentes subjetivos do indivíduo e dos sistemas coletivos (e, portanto, passíveis de serem estudados objetivamente), a dimensão exterior, quer em sua vertente individual, quer em sua vertente coletiva, tem sido exaustivamente priorizada na investigação científica e empírica que, pelos valores que passou a defender, não se propõe a considerar a relação de seus componentes com os componentes das dimensões interiores.

Ao pensar a ludicidade como uma experiência interna do sujeito, Luckesi situa a compreensão desse fenômeno na dimensão interior individual, ou seja, no quadrante superior esquerdo, conforme propõe Wilber, diferenciando-a das atividades lúdicas, passíveis de estudo em qualquer uma das dimensões. Como explica aquele autor, não se trata, em sua compreensão, de conceber a ludicidade como sinônimo de atividades lúdicas, pensando-as a partir de suas características histórico-culturais ou histórico-sociais (o que localizaria o estudo na perspectiva exterior coletiva, ou no quadrante direito inferior), nem de abordar as funções terapêuticas e/ou educativas associadas a essas atividades (no caso, estudos realizados na dimensão exterior individual, localizada no quadrante direito superior). Para Luckesi (2002), pois,

[...] quando estamos definindo ludicidade como um estado de consciência, onde se dá uma experiência em estado de plenitude, não estamos falando, em si, das atividades objetivas que podem ser descritas sociológica e 
culturalmente como atividade lúdica, como jogos ou coisa semelhante. Estamos, sim, falando do estado interno do sujeito que vivencia a experiência lúdica. Mesmo quando o sujeito está vivenciando essa experiência com outros, a ludicidade é interna; a partilha e a convivência poderá lhe oferecer, e certamente oferece, sensações do prazer da convivência, mas, ainda assim, esta sensação é interna a cada um, ainda que o grupo possa harmonizar-se nessa sensação comum [...]. [...] A descritiva comportamental individual ou coletiva, assim como os valores comunitários que sustentam esta experiência, compõem o entorno dessa sensação de experiência plena, a serem tratadas por outros âmbitos de conhecimentos [...]. (LUCKESI, 2002, p. 31, 33).

Essas reflexões trazem uma grande contribuição para o binômio educação e ludicidade, possibilitando uma compreensão mais abrangente do que vem a ser uma "educação lúdica": aquela que, transcendendo o viés estritamente racionalista que tem caracterizado a educação e orientando-se para o desenvolvimento cognitivo, emocional, ético, criativo físico do educando como um ser humano multidimensional, compromete-se com a promoção de aprendizagens significativas que possam envolver o estudante por inteiro, propiciando, assim, a integração harmônica do seu pensar/sentir/fazer.

Nessa perspectiva, pois, a mera utilização de jogos ou brincadeiras em sala de aula, ou a eleição de estratégias metodológicas não convencionais que se utilizam de atividades brincantes como acessórios para facilitar a aquisição de conteúdos formais, como ocasionalmente acontece no meio educacional convencional, está muito distante de corresponder aos ideais de uma educação lúdica, uma vez que ainda persiste o caráter instrumental do ensino, priorizando, mesmo que dissimuladamente, a racionalidade do educando...

\section{A Pedagogia Waldorf: princípios e fundamentos}

Na contramão da tendência comumente observada nos meios educacionais formais, que concebe equivocadamente a relação entre educação e ludicidade a partir da simples utilização de metodologias brincantes no contexto educativo, desconsiderando a necessidade de se superar a concepção instrumental do ensino e, portanto, reorientar a prática pedagógica para o desenvolvimento global dos educandos e para a multidimensionalidade do processo educativo, destaca-se a Pedagogia Waldorf. 
No início do século XX, Rudolf Steiner, o idealizador da Pedagogia Waldorf, já chamava a atenção para o caminho percorrido pela educação moderna ao desapropriar a realidade subjetiva e interior do educando em prol do cultivo de uma racionalidade objetiva e dissociada da totalidade e da complexidade da experiência humana. Ancorando-se na Antroposofia ${ }^{3}$, Steiner (2003) inaugura um modelo de educação que visa atender à formação de crianças e adolescentes a partir de uma concepção integral do ser humano efetivamente espelhada em uma práxis pedagógica que atua no sentido de buscar uma unidade harmônica no desenvolvimento bio-psicoemocional e espiritual do educando.

Segundo a Antroposofia, o ser humano é uma entidade constituída de corpo, alma e espírito - aos quais estão relacionadas, respectivamente, as faculdades do fazer, do sentir e do pensar. Embora latentes desde o momento no nascimento físico do homem, cada um desses constituintes tem um desabrochar que segue uma progressão baseada em ciclos de sete anos, denominados "setênios". Uma vez que, a cada novo setênio, a energia vital do ser humano apresenta-se especialmente investida em um aspecto específico desse desenvolvimento, acarretando modificações biológicas, fisiológicas e cognitivas peculiares, todo o currículo Waldorf apresenta-se também orientado para atitudes e dispositivos didático-metodológicos diferenciados em cada uma dessas etapas. (STEINER, 2003).

No primeiro setênio (0-7 anos), como esclarece Gudrun Burkhard (2000), o cenário de desenvolvimento infantil tem como pano de fundo a reestruturação das substâncias herdadas e a individuação somática, orientadas pela própria individualidade. É o período em que todas as energias da criança estão investidas no seu desenvolvimento físico, exigindo-lhe intensa atividade corporal. Assim, a educação infantil Waldorf prioriza o movimento, a experiência corporal que faz uso da motricidade, como também o movimento da imaginação, da fantasia da criança, pois compreende que o movimento da criança será a base para não apenas o seu desenvolvimento físico e motor, mas também para o seu desenvolvimento emocional, neurológico e até mesmo cognitivo, preparando as estruturas neurológicas para a aprendizagem a ser requerida posteriormente em seu processo de escolarização.

Contrariando a atual vocação da educação infantil, que orientada pelo signo do pensar intelectual utilitarista tem-se caracterizado por estimular a alfabetização linguística e matemática precocemente, a Pedagogia Waldorf defende que, uma vez que nesse estágio de desenvolvimento as crianças ainda

3 A Antroposofia é um método de conhecimento científico, filosófico e espiritual também elaborado por Rudolf Steiner para compreender a natureza, o ser humano e o universo, que se caracteriza por integrar e transcender o conhecimento científico produzido pela cosmovisão materialista e cientificista. 
não apresentam habilidades mentais necessárias à manipulação de símbolos, já que os prolongamentos de seus neurônios não completaram o processo de mielinização ${ }^{4}$, as crianças só sejam alfabetizadas a partir dos seis anos e meio ${ }^{5}$.

Concluído o processo de maturação orgânica, o foco do desenvolvimento, no segundo setênio (7-14 anos), volta-se para o funcionamento psicoemocional da criança, mobilizando suas faculdades psíquicas (para possibilitar a sua progressiva utilização a serviço do pensamento e da aprendizagem) e, ao mesmo tempo, proporcionando uma intensa vivência emocional (favorecida pelo desenvolvimento das suas emoções, dos seus sentimentos).

Assim, embora nesse momento de seu desenvolvimento a criança já evidencie que consegue raciocinar aproximando-se da lógica adulta, os seus esquemas conceituais e ações executadas mentalmente ainda necessitam ser manipulados ou imaginados de forma concreta ${ }^{6}$. Em atenção e respeito a esta especificidade no desenvolvimento do educando, o processo de ensino-aprendizagem no ensino fundamental Waldorfé conduzido não de forma abstrata e teórica, como é a tônica no sistema convencional de ensino, mas a partir da vivência, da observação e da descrição dos fenômenos.

Ademais, em consonância com a disposição sentimental e estética latente nos educandos que perpassam por esta fase, o currículo Waldorf elege a arte como o pilar primordial de toda a educação. Segundo Kügelgen (1989), na Pedagogia Waldorf não há nenhum domínio de aprendizagem que não seja enriquecido pela atividade artística, através da qual se aprofunda a experiência. Entretanto, não se reserva um horário determinado para essas atividades, elas não ocorrem à margem dos demais estudos, como usualmente acontece na grande maioria das escolas convencionais que reservam algum espaço do currículo para a arte; ao contrário, são "o laço de união entre as diversas matérias". Aliás, o lugar atribuído

4 Trata-se do processo de revestimento dos axônios por uma capa ou bainha de mielina, substância lipoproteica que possibilita aumentar a velocidade da transmissão dos estímulos nervosos ou impulsos elétricos (sinapses), atribuindo maior eficiência na transmissão da informação pelos neurotransmissores. Uma vez que o processo de mielinização, que se inicia ainda no período embrionário, mais precisamente no sétimo mês de gravidez, estende-se até os seis/sete anos, a alfabetização precoce, ao estimular demasiadamente uma parte do cérebro racional, proporciona um grande desgaste para o sistema nervoso central, de modo a favorecer, posteriormente, o desenvolvimento de patologias degenerativas.

5 Essa orientação, inclusive, está de acordo com o que diz Piaget $(1967,1975)$ em seus estudos sobre o desenvolvimento cognitivo, segundo os quais até os seis/sete anos as crianças encontram-se no estágio pré-operacional, não demonstrando possuir recursos cognitivos e/ou neurológicos para operações objetivas.

6 Assim como Steiner, também Piaget $(1967,1975)$, em sua teoria psicogenética, compreende que no período dos 6/7 até os 12 anos, a que denomina de estágio operatório concreto, embora já manipule objetos da realidade, aproximando-se das regras, das operações lógicas, a criança ainda não o faz com abstração característica da próxima etapa, o estágio das operações formais ou abstratas. 
à arte apresenta-se muito bem configurado no pensamento de Steiner (2003, p. 125): "a pedagogia não pode ser uma ciência - deve ser uma arte. E onde existe uma arte que se possa aprender sem viver constantemente em sentimentos?".

No período que se inicia aos catorze anos, e correspondente ao terceiro setênio (14-21 anos), as energias liberadas da função de desenvolvimento do sistema psicoemocional são, então, destinadas ao despertar das forças do pensar lógico, abstrato e conceitual do indivíduo, base para a formação do seu julgamento pessoal: é a fase do desabrochar da individualidade do educando - para Steiner, do seu constituinte espiritual.

Nessa etapa de seu desenvolvimento, o adolescente busca uma compreensão mais intelectual da vida e seus fenômenos. Essa demanda encontra ressonância num ensino médio Waldorf que estimula o seu espírito mais lógico. Como esclarece Rudolf Lanz (2003), enquanto no ensino fundamental os conteúdos giravam em torno da realidade (e não da abstração), proporcionando ao estudante observar os fenômenos e descrevê-los, nesse novo ciclo do currículo, o ensino Waldorf volta-se para a abordagem das teorias conceitualmente, objetivando compreender a realidade através de princípios verificáveis e mostrar as possíveis explicações para os seus fenômenos.

É que, de acordo com a Antroposofia, somente nesse setênio se deve iniciar o estudo das abordagens de teorias puramente formais, pois é agora que o sistema neurossensorial do jovem apresenta uma maturação necessária para cumprir esta tarefa sem prejudicar o seu desenvolvimento físico e/ou psicoemocional; só então é que ele apresenta maturidade suficiente para encarar o mundo do ponto de vista conceitual ${ }^{7}$.

Assim como as diretrizes curriculares para a educação infantil, o ensino fundamental e o ensino médio Waldorf são organizados, respectivamente, de modo a articularem-se com e atenderem (a)o desenvolvimento dos aspectos volitivos (agir/fazer), psicoemocionais (sentir) e cognitivos (pensar) do educando, também a orientação didático-metodológica de cada aula, na Pedagogia Waldorf, busca a harmonização da tríade pensar, sentir, fazer, evitando-se a unilateralidade em uma ou outra esfera de atividade, e procurando um equilíbrio entre os conteúdos formais, as atividades artísticas (e/ou artesanais) e as atividades corporais. (FEWB, 1999; MIZOGUCHI, 2006).

Por conseguinte, toda aula, nas escolas Waldorf, é organizada de modo a promover a alternância entre a atividade mais intelectualizada e as atividades práticas ou artísticas: o ensino teórico é sempre acompanhado, por um lado,

7 Também para Piaget $(1967,1975)$, é nesse estágio, que denomina de estágio das operações formais ou abstratas, que o adolescente apresenta estruturas mentais que o permitem realizar operações baseadas num tipo de raciocínio abstrato. 
pelo enfoque prático (ênfase nas atividades corporais e artesanais) e, por outro, pelas atividades artísticas que, como sinalizado, no currículo Waldorf são um veículo didático para todas as matérias. Assim, o desenho, a pintura em aquarela, a música, o canto, o teatro, a modelagem em argila, a arte da fala ${ }^{8}$, a euritmia ${ }^{9}$, por um lado, e os trabalhos manuais (tricô, crochê), o desenho de forma, a marcenaria, a educação física, a jardinagem, por outro, são trabalhados no cotidiano escolar de forma bastante articulada com os conteúdos formais de cada época ${ }^{10}$ e com as demandas psicoemocionais do educando, de acordo com cada fase de seu desenvolvimento, para que se vivencie o aprendizado de forma significativa.

A partir do que nos ensinou Luckesi, podemos dizer que uma educação lúdica pode ser compreendida como aquela que propicia a plenitude da experiência formativa, requerendo um profundo envolvimento dos implicados ao reivindicar não apenas a sua racionalidade, mas sua presença "inteira" em sala de aula: pensar, sentir e fazer integrados e, em uníssono, favorecendo e estimulando aprendizagens verdadeiramente significativas. Como vimos, pois, a grande contribuição da Pedagogia Waldorf é demonstrar, em sua organização curricular e metodológica, um caminho efetivamente em curso em direção à integração entre pensar, sentir e fazer no âmbito da educação formal, de modo a atender verdadeiramente os pressupostos essenciais da educação lúdica.

\section{A Pedagogia lúdica Waldorf: trançando os fios desta conversa...}

O paradigma educacional emergente, consoante com o movimento científico da contemporaneidade, tem sinalizado a importância de se pensar e, sobretudo, se fazer uma educação voltada para o desenvolvimento integral dos educandos, de modo a superar a orientação positivista e mecanicista que, há séculos, vem caracterizando nosso modelo de educação.

Apresentando sua contribuição para esse processo, Luckesi (2005b) busca auxiliar na compreensão do significado do que vem a ser "uma educação inte-

8 A Arte da Fala é uma atividade que explora os sons das palavras dispostas poeticamente, enfatizando os fonemas do ponto de vista rítmico ou a métrica implícita em versos intencionalmente selecionados.

9 A Euritmia é uma arte de movimento corporal criada por indicação de Rudolf Steiner.

10 Diferentemente da rotina escolar convencional, quando em um turno se sucedem aulas de várias matérias, na Pedagogia Waldorf, durante o período de aproximadamente um mês, uma única matéria é destacada como tema principal, de modo que as demais atividades que compõem o currículo são a ela relacionadas com o intuito de complementá-la, sob perspectiva interdisciplinar. 
gral do ser humano", definindo-a como a prática formativa que, ao contrário do que caracterizou a educação moderna e mecanicista, apresenta-se imbuída do desenvolvimento das múltiplas dimensões do educando - a cognitiva, a afetiva, a social, a estética, a ética... Para o autor, que compreende o fenômeno da ludicidade como sinônimo da experiência interna do sujeito ao vivenciar ou realizar algo com a máxima integração possível entre o seu pensar, o seu sentir e o seu fazer (LUCKESI, 2000, 2005a, b), uma educação que se propõe a transcender o ensino instrumental e conteudista, ou que, em outra palavras, pode ser considerada como um educação integral ou global, é, portanto, centrada na ludicidade - o que equivale a dizer que é uma educação lúdica.

Transcendendo a visão atomística de mundo e de ser humano; buscando uma compreensão mais orgânica e complexa do homem e dos fenômenos a ele associados; considerando o educando mais do que um ente puramente pensante e concebendo-o como uma individualidade que apresenta um corpo físico, uma alma e um espírito; apresentando-se didático e metodologicamente orientada para a harmonização do pensar/sentir/agir desses educandos, destituindo o hiato entre o teórico e o prático, entre corpo, emoções/sentimentos e desenvolvimento cognitivo; elegendo a arte e a experiência estética como a estratégia primordial da sua educação; sustentando uma proposta interdisciplinar não apenas do ponto de vista dos seus fundamentos teórico-epistemológicos, mas em sua efetiva organização didático-metodológica, a Pedagogia Waldorf tem demonstrado, pois, preencher os requisitos e fundamentos de uma educação lúdica, superando o reducionismo e a fragmentação típicos da tradição epistemológica moderna e, deste modo, apresentando-se consoante com os pressupostos que norteiam a proposta educacional voltada para o século XXI.

\section{REFERÊNCIAS}

ANDRADE E SILVA, Dulciene Anjos de. Por uma Educação Voltada para o Desenvolvimento da Expressão Oral dos Educandos: um estudo sobre a Pedagogia Waldorf. Tese (Doutorado em Educação) - Universidade Federal da Bahia, Salvador, 2010.

BURKHARD, Gudrun. Tomar a Vida nas Próprias Mãos. Como trabalhar na própria biografia o conhecimento das leis gerais do desenvolvimento humano. São Paulo: Antroposófica, 2000.

DELORS, Jacques. Educação: Um Tesouro a Descobrir. São Paulo: Cortez; Brasília: MEC/UNESCO, 2001. 
FEWB. Federação das Escolas Waldorf do Brasil. Para a Estruturação do Ensino do $1^{\circ}$ ao $8^{\circ}$ ano nas Escolas Waldorf. São Paulo: FEWB, 1999.

KÜGELGEN, Helmut von. A Educação Waldorf. Aspectos da Prática Pedagógica. São Paulo: Antroposófica, 1989.

LANZ, Rudolf. A Pedagogia Waldorf. Caminho para um Ensino mais Humano. São Paulo: Antroposófica, 2003.

LUCKESI, Cipriano C. Educação, Ludicidade e Prevenção das Neuroses Futuras: uma Proposta Pedagógica a partir da Biossíntese. Ludopedagogia, Salvador, BA: UFBA/ FACED/PPGE, v. 1, p. 9-42, 2000.

LUCKESI, Cipriano C. Ludicidade e atividades lúdicas: uma abordagem a partir da experiência interna. Salvador, 2005a. Disponível em: <http://www.luckesi.com.br/ artigoseducacao.htm>. Acesso em: 10 ago. 2014.

LUCKESI, Cipriano C. Apontamentos para uma visão integral da prática educativa. Salvador, 2005b. Disponível em: <http://www.luckesi.com.br/artigoseducacao.htm>. Acesso em: 21 nov. 2014.

MIZOGUCHI, Shigueyo M. Rudolf Steiner e a Pedagogia Waldorf. In: Viver Mente \& Cérebro. São Paulo: Duetto Editorial. 2006. Coleção Memória da Pedagogia, v. 6.

PIAGET, Jean. O raciocínio na criança. Rio de Janeiro: Record, 1967.

PIAGET, Jean. A formação do símbolo na criança. Rio de Janeiro: Zahar, 1975.

SCHILLER, Friedrich von. A Educação Estética do Homem. São Paulo: Iluminuras, 2002.

SETZER, Waldemar. Rudolf Steiner - biografia cronológica. São Paulo, 2003. Disponível em: <http://www.sab.org.br/steiner/biogr.htm.Versão 1.7>. Acesso em: 20 out. 2008.

STEINER, Rudolf. A Arte da Educação I: O Estudo Geral do Homem - uma base para a Pedagogia. São Paulo: Antroposófica, 2003.

WILBER, Ken. A União da Alma e dos Sentidos. Integrando Ciência e Religião. São Paulo: Cultrix, 1998.

Texto recebido em 21 de maio de 2015. Texto aprovado em 12 de junho de 2015. 
